\title{
RESEARCH
}

Open Access

\section{Dectin-1/Syk signaling triggers neuroinflammation after ischemic stroke in mice}

Xin-Chun Ye ${ }^{1^{* \dagger}}$, Qi Hao ${ }^{2+}$, Wei-Jing Ma ${ }^{1+}$, Qiu-Chen Zhao ${ }^{3}$, Wei-Wei Wang ${ }^{4}$, Han-Han Yin ${ }^{1}$, Tao Zhang ${ }^{1}$, Miao Wang ${ }^{1}$, Kun Zan ${ }^{1}$, Xin-Xin Yang ${ }^{1}$, Zuo-Hui Zhang ${ }^{1}$, Hong-Juan Shi ${ }^{1}$, Jie Zu ${ }^{1}$, Hafiz Khuram Raza', Xue-Ling Zhang ${ }^{5}$, De-Qin Geng ${ }^{1}$, Jin-Xia Hü ${ }^{* *}$ and Gui-Yun Cui ${ }^{*}$

\begin{abstract}
Background: Dendritic cell-associated C-type lectin-1 (Dectin-1) receptor has been reported to be involved in neuroinflammation in Alzheimer's disease and traumatic brain injury. The present study was designed to investigate the role of Dectin-1 and its downstream target spleen tyrosine kinase (Syk) in early brain injury after ischemic stroke using a focal cortex ischemic stroke model.

Methods: Adult male C57BL/6 J mice were subjected to a cerebral focal ischemia model of ischemic stroke. The neurological score, adhesive removal test, and foot-fault test were evaluated on days 1, 3, 5, and 7 after ischemic stroke. Dectin-1, Syk, phosphorylated (p)-Syk, tumor necrosis factor-a (TNF-a), and inducible nitric oxide synthase (iNOS) expression was analyzed via western blotting in ischemic brain tissue after ischemic stroke and in BV2 microglial cells subjected to oxygen-glucose deprivation/reoxygenation (OGD/R) injury in vitro. The brain infarct volume and Iba1-positive cells were evaluated using Nissl's and immunofluorescence staining, respectively. The Dectin-1 antagonist laminarin (LAM) and a selective inhibitor of Syk phosphorylation (piceatannol; PIC) were used for the intervention.

Results: Dectin-1, Syk, and p-Syk expression was significantly enhanced on days 3, 5, and 7 and peaked on day 3 after ischemic stroke. The Dectin-1 antagonist LAM or Syk inhibitor PIC decreased the number of Iba1-positive cells and TNF-a and iNOS expression, decreased the brain infarct volume, and improved neurological functions on day 3 after ischemic stroke. In addition, the in vitro data revealed that Dectin-1, Syk, and p-Syk expression was increased following the 3-h OGD and 0, 3, and $6 \mathrm{~h}$ of reperfusion in BV2 microglial cells. LAM and PIC also decreased TNF-a and iNOS expression $3 \mathrm{~h}$ after OGD/R induction.
\end{abstract}

Conclusion: Dectin-1/Syk signaling plays a crucial role in inflammatory activation after ischemic stroke, and further investigation of Dectin-1/Syk signaling in stroke is warranted.

Keywords: Dectin-1, Syk, inflammation, ischemic stroke

\footnotetext{
*Correspondence: xinchunye@xzhmu.edu.cn; jinxia0819@163.com; guiyuncui@foxmail.com

${ }^{+}$Xin-Chun Ye, Qi Hao and Wei-Jing Ma contributed equally to this work.

${ }^{1}$ Institute of Stroke Center and Department of Neurology, The Affiliated

Hospital of Xuzhou Medical University, Xuzhou Medical University, Xuzhou,

People's Republic of China

Full list of author information is available at the end of the article
}

(c) The Author(s). 2020 Open Access This article is distributed under the terms of the Creative Commons Attribution 4.0 International License (http://creativecommons.org/licenses/by/4.0/), which permits unrestricted use, distribution, and reproduction in any medium, provided you give appropriate credit to the original author(s) and the source, provide a link to the Creative Commons license, and indicate if changes were made. The Creative Commons Public Domain Dedication waiver (http://creativecommons.org/publicdomain/zero/1.0/) applies to the data made available in this article, unless otherwise stated. 


\section{Introduction}

In recent decades, ischemic stroke has become one of the most common causes of disability and mortality worldwide. Although the pathophysiology of cerebral ischemic injury is multifactorial, increasing studies have suggested that the inflammatory response plays a crucial role in stroke progression $[1,2]$. Inflammation in the brain parenchyma after cerebral ischemia is mediated by neurons, endothelial cells, microglia, and other immune cells [3], and inhibition of inflammatory responses has been demonstrated to improve the outcome following a stroke [4, 5]. However, the detailed mechanisms by which the inflammatory response is triggered after a stroke remain largely unknown.

Dendritic cell (DC)-associated C-type lectin-1 (Dectin-1) has been identified as an immune-receptor tyrosine-based activation motif (ITAM)-coupled C-type lectin receptor (CLR). Dectin-1 recognizes various danger-associated molecular patterns (DAMPs) and triggers inflammatory signals by recruiting its downstream molecular tyrosine kinase (spleen tyrosine kinase; Syk) [6-8]. Dectin-1 is a type II transmembrane receptor that is expressed on different cell types during inflammation, including DCs, neutrophils, monocytes, $\mathrm{T}$ cells, and epithelial cells [9-12]. Previous studies have reported that immune receptors that initiate the inflammatory response play an important role in stroke progression [13-16]. However, to the best of our knowledge, whether the immune receptor Dectin-1 is involved in the inflammatory response following a stroke has not yet been investigated.

Syk is a nonreceptor protein tyrosine kinase that is observed extensively in hematopoietic and nonhematopoietic cells $[17,18]$. It possesses tandem $\mathrm{N}$-terminal src homology-2 (SH2) domains that can bind to ITAMs [19, 20]. Incomplete ITAMs, referred to as hemITAMs, can interact with Syk and mediate its activation [21]. A number of C-type lectin receptors, such as Dectin-1, C-type lectin-like receptor 2 (CLEC2), and C-type lectin domain-containing 9A (CLEC9A), possess hemITAMs and transduce signals through Syk [22]. Syk has been reported to play an indispensable role in acute and chronic inflammation, and inhibition of Syk impedes brain tissue damage following an ischemic stroke [23-26]. However, to the best of our knowledge, the specific role of Dectin1 and its downstream target Syk in ischemic stroke has not yet been investigated.

The present study revealed that the Dectin-1/Syk pathway is involved in neuroinflammation following ischemic stroke. Changes in Dectin-1, Syk, p-Syk, TNF- $\alpha$, and inducible nitric oxide synthase (iNOS) expression following ischemic stroke were evaluated both in vivo and in vitro. In addition, the present study investigated whether the Dectin-1 antagonist laminarin (LAM) or the Syk inhibitor piceatannol (PIC) could partly reverse neuroinflammation following ischemic stroke in mice. The working model for the present study is presented in Fig. 1.

\section{Materials and methods \\ Cerebral focal ischemia}

Adult male C57BL/6 J mice (weight, 22-30 g) were purchased from the Shanghai Experimental Animal Center of the Chinese Academy of Sciences (Shanghai, China). The cerebral focal ischemia model was induced by photothrombotic ischemia as previously described [27]. The main steps are as follows: The mice were injected with $1 \%$ Rose Bengal $[100 \mathrm{mg} / \mathrm{kg}$ intraperitoneally (i.p.) dissolved in $0.9 \%$ saline] (Sigma-Aldrich; Merck KGaA) following induction of anesthesia with $10 \%$ chloral hydrate $[300 \mathrm{mg} / \mathrm{kg}$ (i.p.) dissolved in $0.9 \%$ saline]. After $10 \mathrm{~min}$, the sensorimotor region, which is located $\sim 2$ $\mathrm{mm}$ lateral to the bregma, was exposed for $15 \mathrm{~min}$ to cold light. In order to investigate the optimal ischemia time, the mice were made ischemic at $6 \mathrm{~h}$ and $1,3,5$, and 7 days. The animals were randomly divided into the following four groups: (i) sham group, (ii) ischemic group with vehicle treatment (ischemia + saline/DMSO

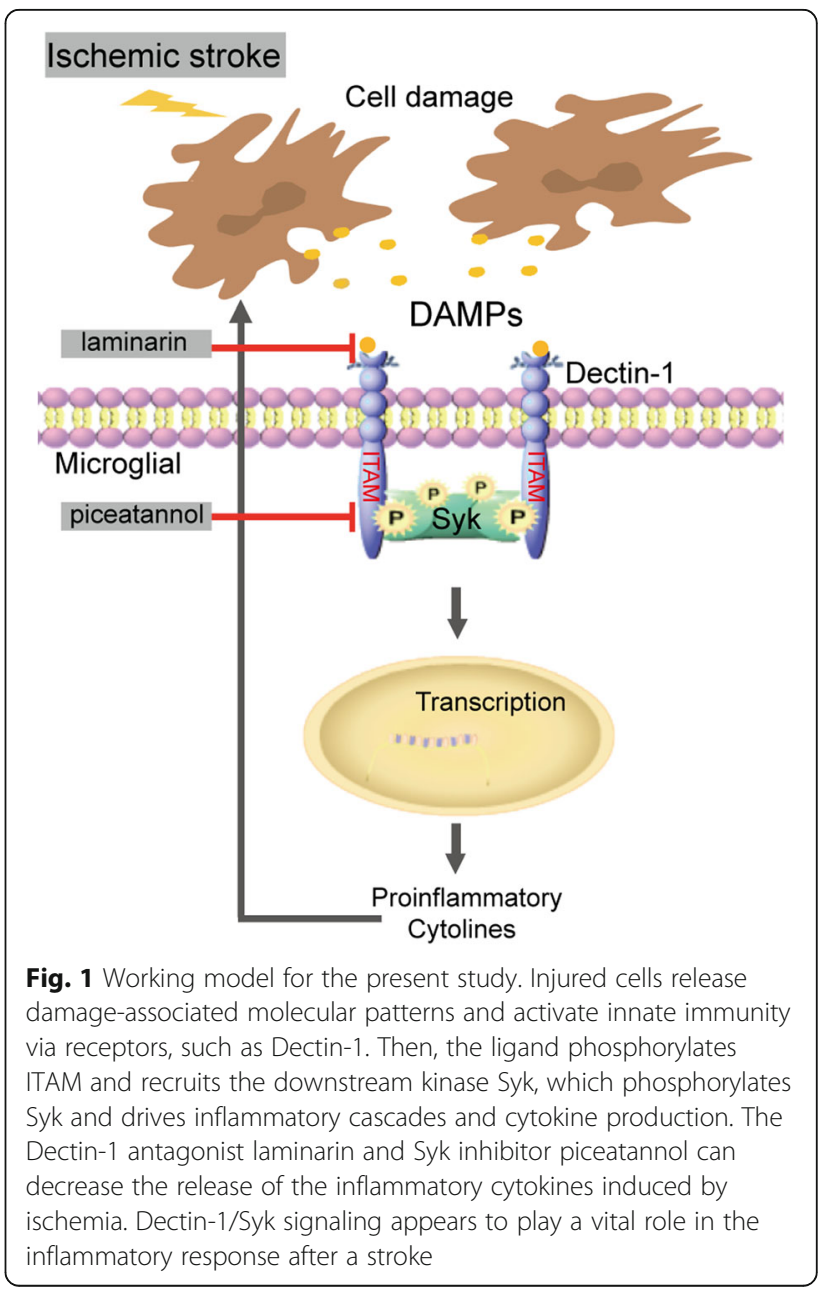


group), (iii) ischemia group, and (iv) Dectin-1 antagonist treatment group/Syk inhibitor treatment group (ischemia + LAM/PIC group).

\section{Neurological function tests}

In all animals, the adhesive removal and foot-fault tests were performed and the modified neurological severity score (mNSS) was obtained before stroke and at 1, 3, 5, and 7 days after stroke with or without LAM/PIC treatment. The mNSS is a composite that is used to assess neurological functions based on motor, sensory, balance, and reflex measures, which are graded on a scale of 0 to 18 (normal score, 0; maximal deficit score, 18); higher scores imply greater neurological injury $[28,29]$.

\section{Analysis of the brain infarct volume}

Formaldehyde-fixed specimens were cut into $50-\mu \mathrm{m}$ thick sections and subjected to Nissl's staining. The sections were placed in 100,95 , and $80 \%$ ethanol for $30 \mathrm{~s}$ each and then treated with FD Cresyl Violet Solution ${ }^{\mathrm{TM}}$ (FD Neoro Technologies) for $2 \mathrm{~min}$. After washing in distilled water, the sections were dehydrated through an alcohol series, cleared in xylene, and coverslipped with neutral resin. In the present study, the stained sections were scanned and the infarct areas measured using the ImageJ software. The total infarct volume was obtained by indirect methods as previously described [27].

\section{Drug administration in vivo and in vitro}

The Dectin-1 receptor antagonist LAM (Sigma-Aldrich; Merck $\mathrm{KGaA}$ ) was diluted to $10 \mathrm{mg} / \mathrm{ml}$ in vehicle (saline) according to the manufacturer's protocol. Then, LAM at $300 \mathrm{mg} / \mathrm{kg} /$ day or the same volume of vehicle (saline) was injected i.p. $1 \mathrm{~h}$ after ischemic stroke and once daily for the 2 subsequent days after the stroke. For the in vitro experiment, the optimal dose of LAM was also assessed (the Additional file 1). Then, BV2 cells were preincubated with LAM for $1 \mathrm{~h}$ before induction with oxygen-glucose deprivation/reoxygenation (OGD/R) or lipopolysaccharide (LPS; $1,000 \mathrm{ng} / \mathrm{ml}$ ).

Similarly, the mice were treated with either the Syk inhibitor (PIC; Selleck Chemicals) or vehicle (DMSO) once daily after ischemic stroke. For the in vivo experiment, the PIC dose was $20 \mathrm{mg} / \mathrm{kg} /$ day. For the in vitro experiments, the optimal dose of PIC was also assessed (Additional file 1). Then, BV2 cells were pretreated with PIC for $1 \mathrm{~h}$ before treatment with or without OGD/R or LPS.

\section{Cell culture and experimental protocols}

BV2 microglial cell line was grown in Dulbecco's modified Eagle's medium (DMEM)/high glucose supplemented with $10 \%$ fetal bovine serum, $100 \mathrm{U} / \mathrm{ml}$ of penicillin, and $100 \mathrm{mg} / \mathrm{l}$ of streptomycin at $37^{\circ} \mathrm{C}$ in a $5 \%$ $\mathrm{CO}_{2}$ incubator. Mouse primary microglial cells were prepared as previously described [30,31]. Briefly, brains were removed from mice at post-natal days $1-3$ and the cortices were triturated into single cells. Mixed glial were plated in $25 \mathrm{~T}$ culture flasks coated with poly-D-lysine and grown in DMEM/F12 with 10\% fetal bovine serum, GlutaMAX (Invitrogen; ThermoFisher Scientific, Inc.) and $1 \%$ penicillin/streptomycin in a $5 \% \mathrm{CO}_{2} / 37^{\circ} \mathrm{C}$ incubator, changing medium after 7 days, for a total of 2 weeks. In order to harvest primary microglial cells, the flask was shaken at $150 \mathrm{rpm}$ for $2 \mathrm{~h}$. The fluid medium was subsequently collected and centrifuged at $1,000 \mathrm{rpm}$ for $10 \mathrm{~min}$. The cell pellets were resuspended to plate 5 $\times 10^{5}$ cells per well onto 6-well plates, and subjected to various treatments within $24 \mathrm{~h}$ of harvest. Cells were pretreated with LAM or PIC for $1 \mathrm{~h}$ and then subjected to $\mathrm{OGD} / \mathrm{R}$ or LPS treatment. For OGD/R, the cells were washed twice with phosphate-buffered saline (PBS), placed in glucose-free DMEM and then exposed to hypoxia $\left(94 \% \mathrm{~N}_{2}, 5 \% \mathrm{CO}_{2}\right.$, and $\left.1 \% \mathrm{O}_{2}\right)$ at $37^{\circ} \mathrm{C}$ in a humidified chamber (ThermoFisher Scientific, Inc.) for $3 \mathrm{~h}$. Then, OGD was terminated, and the cells were exposed to normal culture conditions $\left(37^{\circ} \mathrm{C}, 95 \%\right.$ air and $5 \%$ $\mathrm{CO}_{2}$ ) for $3 \mathrm{~h}$. For LPS treatment, the cells were exposed to LPS after $1 \mathrm{~h}$ of LAM or PIC treatment, followed by incubation under normal culture conditions for $24 \mathrm{~h}$. Then, the BV2 cells were randomly divided into the following groups: (i) normal control group (control group), (ii) LAM-pretreated control group (control + LAM group), (iii) OGD/R or LPS group, (iv) LAM-pretreated OGD/R or LAM-pretreated LPS group (LAM + OGD/R or LPS group), (v) PIC-pretreated control group (control + PIC group), and (vi) PIC-pretreated OGD/R or LPS group (PIC + OGD/R or LPS group).

\section{RNA interference experiment}

The siRNA gene silencing in BV2 cells was performed as previously described [32]. Briefly, BV2 cells were seeded into a 6-well plate (Corning Inc.) at a density of $1.5 \times$ $10^{5}$ cells/well $24 \mathrm{~h}$ prior to transfection. BV2 cells were transfected by Lipofectamine 2000 (Invitrogen; Thermo Fisher Scientific, Inc.) with siRNAs targeting to Dectin-1 (sense: 5'-GGGAAGAGCUGUUACCUAUTT-3'; antisense: 5'-AUAGGUAACAGCUCUUCCCTT-3'), Syk (sense: 5'-CCUGCUGCACGAAAGGGAAATT-3'; antisense: $5^{\prime}$-UUUCCCUUCGUGCAGCAGGTT-3') or control siRNA (sense: 5'-UUCUCCGAACGUGU CACGUTT-3'; antisense: 5' -ACGUGACACGUUCGGA GAATT- $3^{\prime}$ ) as the negative control. Two days after transfection, the knockdown efficiency of siRNA was determined via western blot analysis. The present study assigned the cells into the following groups: (i) control siRNA group, (ii) Dectin-1 or Syk siRNA group, (iii) OGD/R + control siRNA group, and (iv) OGD/R + Dectin-1 or Syk siRNA group. 


\section{Western blotting}

Total proteins from the ischemic cortical area brain tissues or BV2 microglial cells were collected in equal amounts of cell lysate, and the separated proteins in the supernatant were subsequently transferred. For immunoblotting, the following primary antibodies were used: Anti-Dectin-1 (1:1,000; Abcam), anti-Syk (1:1,000; Cell Signaling Technology, Inc.), anti-p-Syk (1:1,000; Cell Signaling Technology, Inc.), anti-TNF- $\alpha$ (1:1,000; Cell Signaling Technology, Inc.), and anti-iNOS (1:1,000; Cell Signaling Technology, Inc.). Western blotting was performed at $6 \mathrm{~h}$ and 3, 5, and 7 days after ischemic stroke for the mouse tissues and at $0,3,6$, and $12 \mathrm{~h}$ after OGD/ $\mathrm{R}$ treatment and $3,6,12$, and $24 \mathrm{~h}$ after LPS treatment for the BV2 microglial cells. Then, the optimal time points of 3 days for the in vivo experiments and $3 \mathrm{~h}$ for OGD/R treatment and $24 \mathrm{~h}$ for LPS treatment in vitro were selected for the subsequent experiments.

\section{Immunofluorescence analysis}

Brain tissue was removed and then immersed in $4 \%$ paraformaldehyde for $5 \mathrm{~h}$ and $20 \%$ sucrose for 3 days at $4{ }^{\circ} \mathrm{C}$ to process the samples for immunofluorescence. Following standard histological procedures, the sections were preincubated with $5 \%$ goat serum at room temperature for $60 \mathrm{~min}$. Subsequently, the sections were incubated overnight at $4{ }^{\circ} \mathrm{C}$ in a mixture containing a rabbit polyclonal anti-Iba1 antibody (1:500; Abcam) and a rat polyclonal anti-CD68 antibody (1:500; Abcam). After washing three times in PBS for $10 \mathrm{~min}$ per wash, the sections were incubated with a fluorescent secondary immunoglobulin G antibody (polyclonal anti-rabbit Alexa Fluor 594-conjugated red antibody; 1:1,000; ProteinTech Group, Inc.) for $2 \mathrm{~h}$ at room temperature. After washing three times in PBS for 10 min per wash, the sections were stained with DAPI, sealed and mounted, and imaged using a fluorescence microscope (Olympus Corporation). The numbers of target cells were counted using the ImageJ software.

\section{Statistical analysis}

The data are presented as the mean \pm standard deviation from three independent experiments. Comparisons between groups were performed using one-way ANOVA followed by the Student-Newman-Keuls test, and changes in the behavioral responses to drug stimuli over time among groups were tested using two-way ANOVA with repeated measures followed by the Bonferroni post

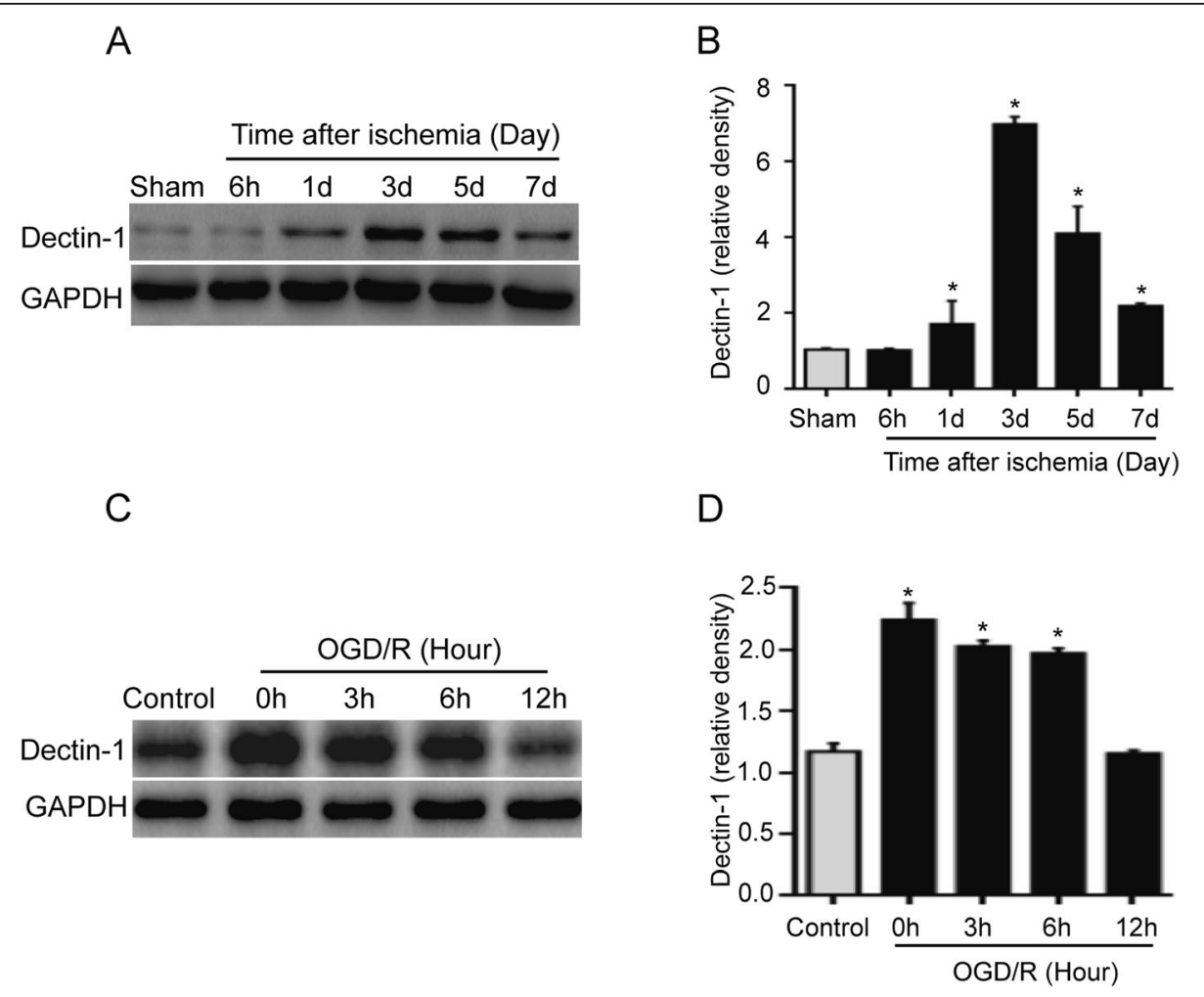

Fig. 2 Dectin-1 expression was increased in ischemic brain tissue after a stroke and BV2 cells with OGD/R-induced injury in vitro. $\mathbf{a}, \mathbf{b}$ The Dectin1 expression level was significantly higher on days 1, 3, 5, and 7 after stroke in the ischemic group compared with in the sham group ( $n=3 /$ group; ${ }^{*} P<0.05$ vs. sham group). $\mathbf{c}$, d The Dectin-1 expression level was significantly higher in BV2 cells with OGD/R exposure for 0,3 , and $6 \mathrm{~h}$ than in those without OGD/R exposure ( $n=3 /$ group; ${ }^{*} P<0.05$ vs. control group) 
hoc test. The statistical significance of differences was analyzed with the SPSS 19.0 software (IBM Corp.). Images were created using GraphPad Prism 6.0 software (GraphPad Software, Inc.). $P<0.05$ was considered to indicate a statistically significant difference.

\section{Results}

Dectin-1 is significantly increased in the ischemic brain tissue after stroke and the BV2 microglial cells after OGD/ R-induced injury in vitro

In order to investigate the potential role of Dectin- 1 in the progression of ischemic stroke, the present study first examined the Dectin-1 protein levels in ischemic brain tissue and BV2 cells in the OGD/R model. Figure $2 \mathrm{a}$, b demonstrates that the Dectin-1 expression level was significantly higher in the ischemic group than in the sham group; the expression level increased significantly at day 1 , peaked at day 3 , and decreased at day 5 after ischemic stroke $(n=3$ / group; $P<0.05)$. Figure $2 \mathrm{c}$, d demonstrates that the Dectin1 expression level was higher in the BV2 cells after 3-h OGD followed by 0,3 , and $6 \mathrm{~h}$ of reperfusion in the OGD/ $\mathrm{R}$ group compared with in the control group cells $(n=3$ / group; $P<0.05)$. These results demonstrate increased Dectin-1 expression in response to a stroke.

Syk and p-Syk are significantly upregulated in the ischemic brain tissue after stroke and BV2 microglial cells with OGD/R-induced injury in vitro

In order to investigate whether Syk signaling was involved in the progression of ischemic stroke, the Syk and p-Syk protein levels were tested in ischemic brain tissue and BV2 cells in the OGD/R model in the present study. Figure $3 \mathrm{a}$, b demonstrates that the Syk expression was significantly increased at days 1, 3, 5, and 7 after the stroke in the ischemic group compared with that of the sham group ( $n=3$ /group; $P<0.05$ ). Additionally, $\mathrm{p}$-Syk expression was significantly enhanced at days 3,5 , and 7 after the stroke. Figure 3c, d shows that the Syk and p-Syk expression levels were higher in the BV2 cells subjected to a 3-h OGD followed by 0-, 3-, or 6-h reperfusion in the OGD/R group compared with those of the control group cells $(n=$ 3/group; $P<0.05$ ). Therefore, the Syk and $\mathrm{p}$-Syk expression levels are enhanced following a stroke, and day 3 after a stroke in the in vivo study, and a 3-h OGD followed by a
A

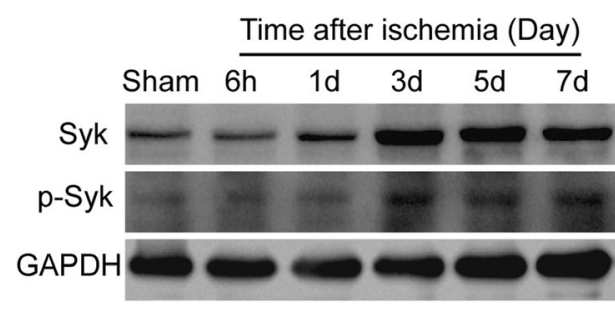

C

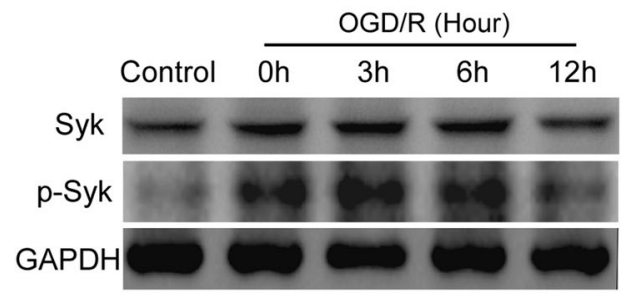

B
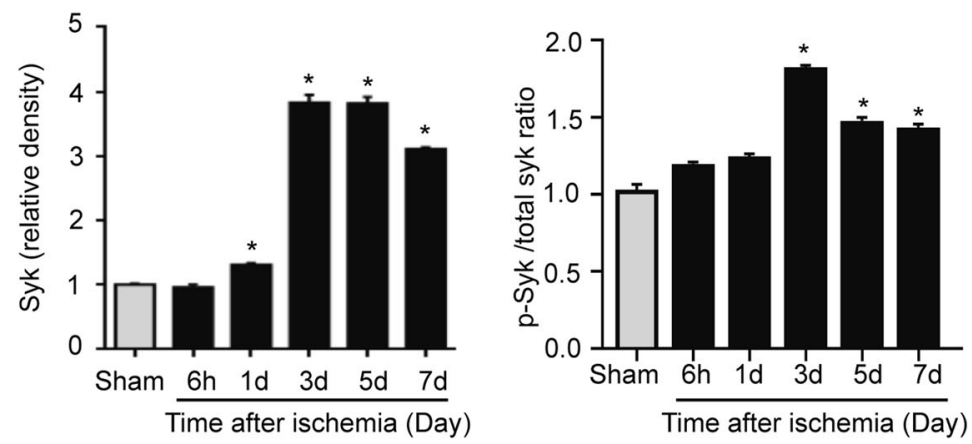

D

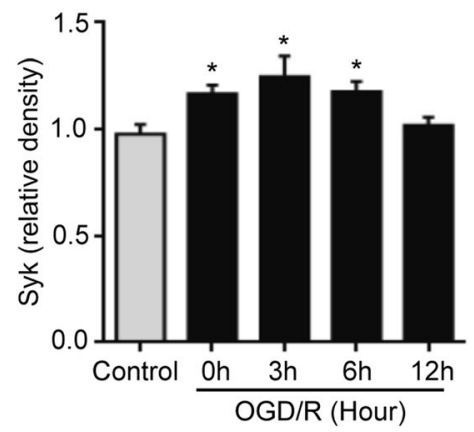

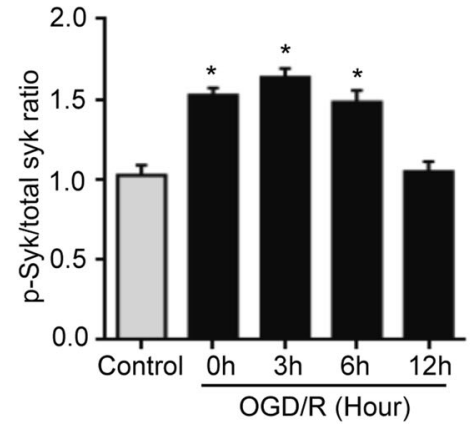

Fig. 3 Syk and p-Syk protein expression was significantly increased in ischemic brain tissue and OGD/R-treated BV2 cells. a, b Syk and p-Syk expression was significantly enhanced on days 1, 3, 5, and 7 after a stroke in the ischemic group compared with that of the sham group $(n=3 /$ group; ${ }^{*} P<0.05$ vs. sham group). c, d BV2 cells with OGD/R exposure for 0,3 , and 6 h showed significantly enhanced Syk and p-Syk expression ( $n$ $=3 /$ group; ${ }^{*} P<0.05$ vs. control group) 
3-h reperfusion in the in vitro study were selected for the subsequent experiments.

\section{Blockage of Dectin-1 rescues the brain infarct volume and neurological impairment after a stroke}

In order to further assess the potential role of Dectin- 1 in ischemic stroke, the present study examined the brain infarct volume and neurological impairment using neurological functional tests in ischemic mice with or without LAM (Dectin-1 antagonist) treatment. Figure 4a, b revealed that the infarct volume was decreased in the ischemic mice with LAM treatment compared with that of the ischemic mice without treatment $(n=3$ /group; $P<0.05)$. Figure $4 \mathrm{c}-\mathrm{e}$ demonstrates that neurological function was significantly improved in the ischemic mice with LAM treatment compared with that of the ischemic mice without treatment $(n=9 /$ group; $P<0.05)$. These results suggest that Dectin-1 may have a deleterious effect on the pathophysiological process of stroke.

\section{Blockade of Decin-1 inhibits Dectin-1/Syk signaling}

In order to further assess the potential role of Dectin-1 in ischemic stroke, Dectin-1/Syk signaling was examined via western blotting. As presented in Fig. 5a, b, Dectin-1 and pSyk expression in the ischemic brain tissue was significantly enhanced in the ischemia and ischemia + saline groups compared with that of the sham group ( $n=3 /$ group; $P<0.05)$. However, LAM (dectin-1 antagonist) treatment significantly decreased Dectin-1 and p-Syk expression in the ischemia group compared with that of the ischemia and the ischemia + saline groups $(n=3$ /group; $P<0.05)$. Dectin-1 and p-Syk expression was significantly increased in the BV2 cells following OGD/R exposure. LAM pretreatment notably decreased the expression of these proteins in the BV2 cells following OGD/R exposure (Fig. 5c, d; $n=3$ / group; $P<0.05$ ). Taken together, these results provide evidence for the potential involvement of Dectin-1/Syk signaling in ischemic stroke.

\section{Blockade of Decin-1 diminishes microglial activation and decreases the expression levels of inflammatory cytokines} In order to further investigate the potential role of Dectin-1 in ischemic stroke, microglial activation was assessed by Iba-1 and CD68 staining, and the expression of inflammatory cytokines was examined via western blotting. 3 days after the stroke, Iba-1- and CD68positive cells were detected in the ischemic brain tissue, although the number of these cells was largely decreased after LAM (dectin-1 antagonist) treatment (Fig. 6a, b). Figure $6 c, d$ demonstrates that TNF- $\alpha$ and iNOS expression was significantly enhanced in the ischemia and ischemia + saline groups compared with that of the sham

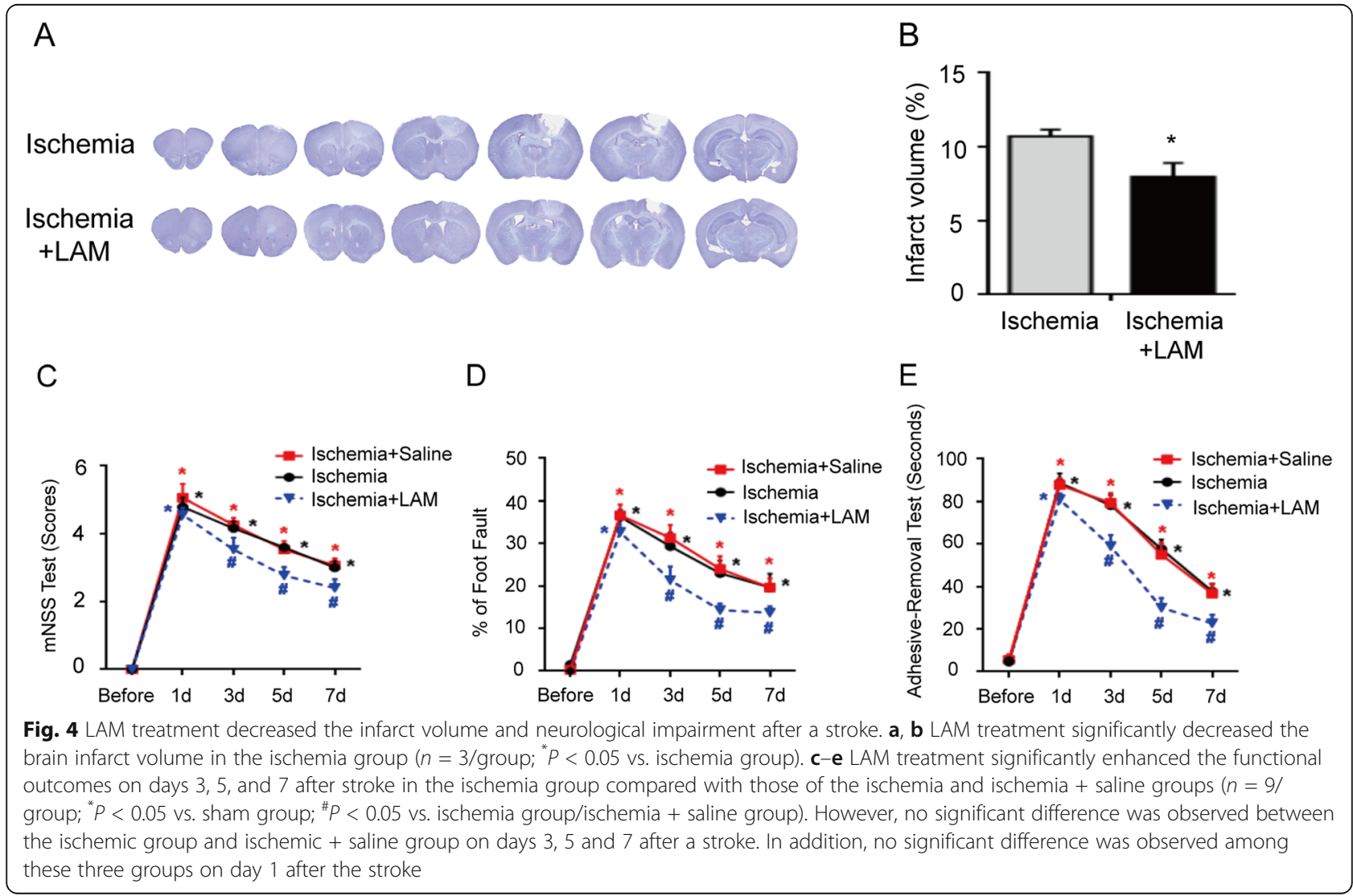




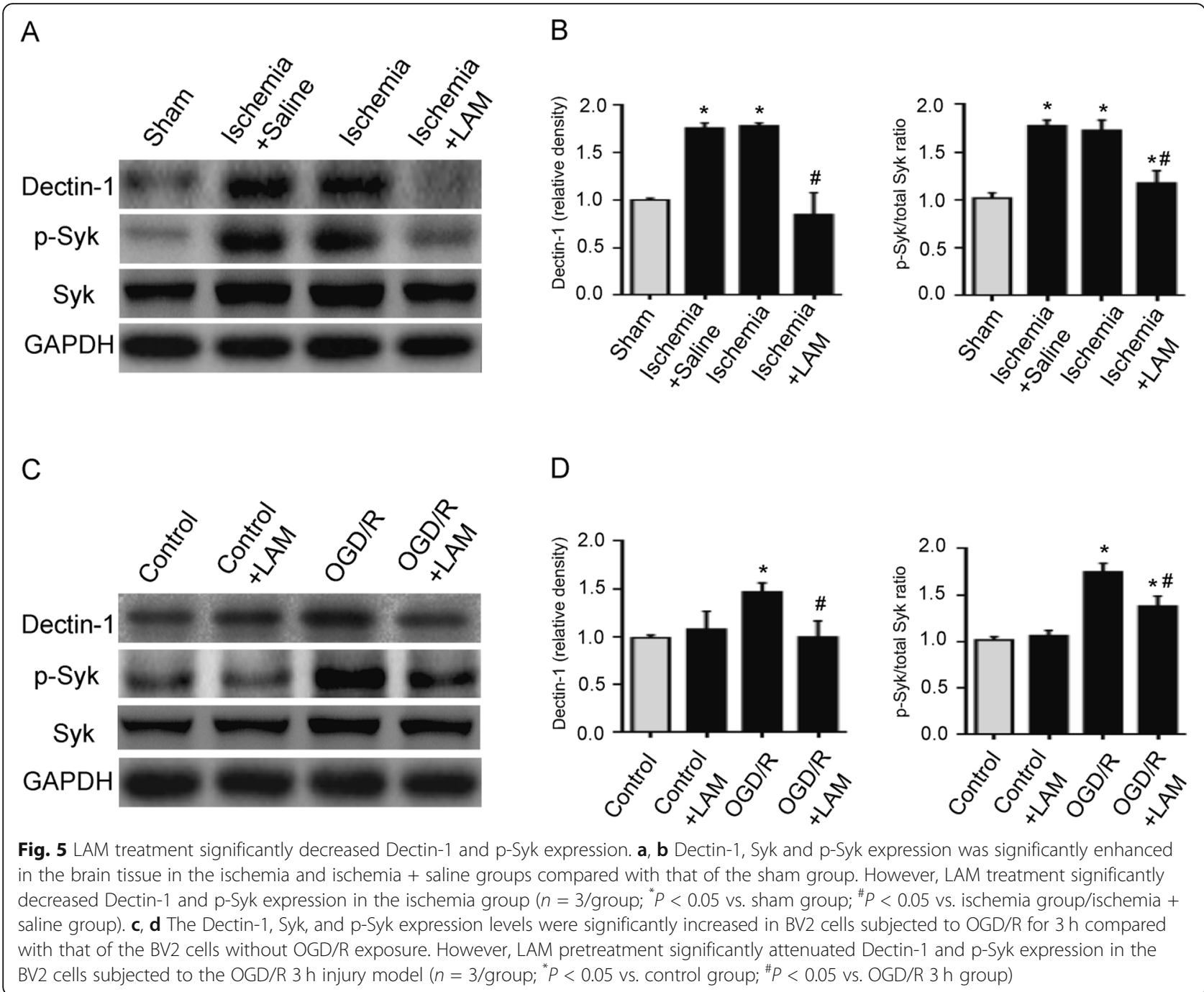

group ( $n=3$ /group; $P<0.05$ ). LAM treatment significantly decreased TNF- $\alpha$ and iNOS expression in the ischemia group compared with that of the ischemia and ischemia + saline groups $(n=3$ /group; $P<0.05)$. Figure 6 e, f shows similar results for BV2 cells exposed to $\mathrm{OGD} / \mathrm{R}$ in the in vitro experiments. Taken together, these results suggest that Dectin-1 is involved in the inflammatory response after a stroke.

Blockade of Syk partly decreases the brain infarct volume and improves the neurological outcomes after a stroke In order to further investigate whether Dectin-1/Syk signaling played a crucial role in the progression of ischemic stroke, PIC (Syk inhibitor) was applied, and the brain infarct volume and neurological functional tests were evaluated. Figure $7 \mathrm{a}, \mathrm{b}$ indicated that the infarct volume was decreased in ischemic mice with PIC treatment compared with that of ischemic mice without treatment ( $n=3$ /group; $P<0.05)$. Figure $7 \mathrm{c}-\mathrm{e}$ shows that functional impairments after stroke were significantly attenuated at days 3,5 , and 7 after PIC treatment in the ischemic stroke model mice compared with those of the mice in the ischemia and ischemia + DMSO groups $(n=9$ /group; $P<0.05)$.

\section{PIC treatment attenuates p-Syk expression in ischemic} brain tissue and in BV2 cells with OGD/R exposure

In order to investigate whether Dectin-1/Syk signaling played a crucial role in the progression of ischemic stroke, PIC (Syk inhibitor) was applied, and Dectin-1/Syk signaling was examined via western blotting in the present study. Figure 8a, b shows that p-Syk expression was significantly enhanced in the ischemic brain tissue in the ischemia and ischemia + DMSO groups compared with that of the sham group. PIC treatment significantly decreased $\mathrm{p}$-Syk expression in the ischemic brain tissue ( $n=3$ /group; " $P<0.05$ vs. sham group; ${ }^{\#} P<0.05$ vs. ischemia group/ischemia + DMSO group). However, PIC treatment failed to decrease Dectin-1 expression in the ischemic brain tissue. Figure $8 \mathrm{c}, \mathrm{d}$ demonstrates 


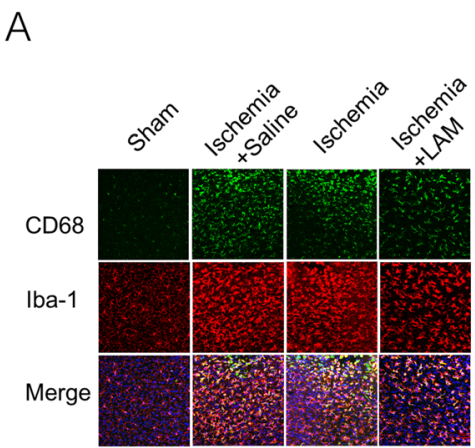

C

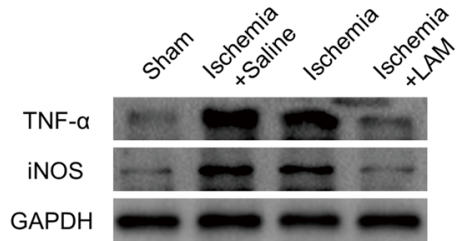

E

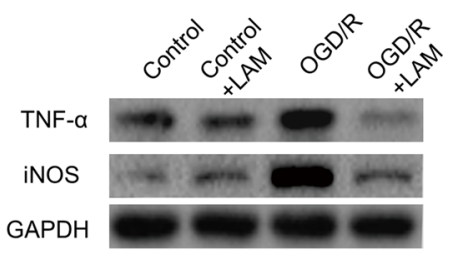

B
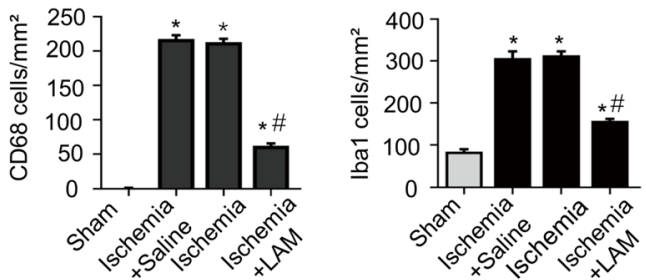

$\mathrm{D}$

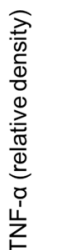

$\mathrm{F}$
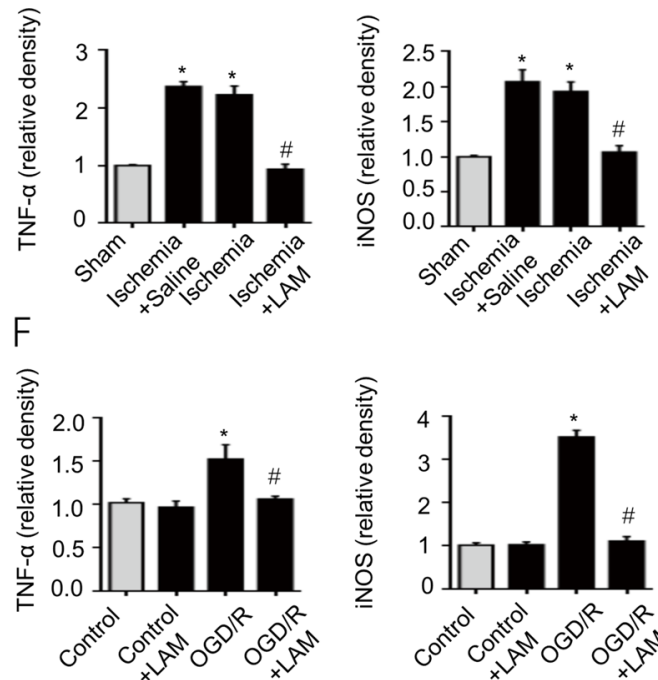

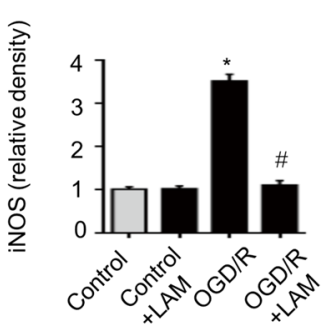

Fig. 6 LAM treatment significantly decreased microglial activation in the ischemic mice and inhibited TNF-a and iNOS expression in the ischemic brain tissue and OGD/R-induced BV2 cells. a, b Microglial activation was assessed by Iba-1 and CD68 staining, and Iba-1- and CD68-positive cells were significantly increased in the ischemia and ischemia + saline groups. LAM treatment significantly attenuated microglial activation (scale bar, $50 \mu \mathrm{m} ; n=3 /$ group; $^{*} P<0.05$ vs. sham group; ${ }^{\#} P<0.05$ vs. ischemia group/ischemia + saline group). $\mathbf{c}$, $\mathbf{d}$ TNF-a and iNOS expression was significantly enhanced in the ischemia and ischemia + saline groups compared with that of the sham group, and LAM treatment significantly inhibited TNF-a and iNOS expression in the ischemia group compared with that of the ischemia and ischemia + saline groups $\left(n=3 /\right.$ group; ${ }^{*} P<$ 0.05 vs. sham group; ${ }^{\# P}<0.05$ vs. ischemia group/ischemia + saline group). However, no significant difference was observed between the ischemia group and ischemia + saline group. e, f TNF-a and iNOS expression was significantly increased in BV2 cells subjected to OGD/R for $3 \mathrm{~h}$ compared with that of cells without OGD/R exposure. LAM pretreatment of BV2 cells with OGD/R exposure significantly decreased the expression of the aforementioned proteins ( $n=3 /$ group; $^{*} P<0.05$ vs. control group; ${ }^{\#} P<0.05$ vs. OGD/R group).

that Dectin-1 and p-Syk expression in BV2 cells with OGD/ $\mathrm{R}$ exposure was significantly increased compared with that of the cells without OGD/R exposure. PIC pretreatment of BV2 cells with OGD/R exposure significantly decreased p-Syk expression ( $n=3$ /group; $P<0.05$ vs. control group; ${ }^{\#} P<0.05$ vs. OGD/R group). However, Dectin-1 expression was not attenuated in the OGD/R-induced BV2 cells with PIC treatment compared with that of the OGD/R-induced BV2 cells without PIC pretreatment.

\section{Decrease of microglial activation and inflammatory cytokine expression by inhibition of Syk signaling} To further study the role of Dectin-1/Syk signaling in ischemic stroke, the Syk inhibitor PIC was used in the present study. Figure 9a, b shows that PIC treatment significantly decreased the numbers of Iba-1- and CD68positive cells in the ischemic brain tissue of the ischemia group compared with that of the ischemia and ischemia + DMSO groups $(n=3 /$ group; $P<0.05)$. Figure $9 \mathrm{c}, \mathrm{d}$ demonstrates that TNF- $\alpha$ and iNOS expression was significantly decreased in the ischemic brain tissue in the ischemia + PIC group compared with that of the ischemia and ischemia + DMSO groups $(n=3 /$ group; $P<$ 0.05). Figure $9 \mathrm{e}, \mathrm{f}$ showed similar results for the BV2 cells with $\mathrm{OGD} / \mathrm{R}$ exposure in the in vitro experiments. Taken together, these results suggest the involvement of Dectin-1/Syk signaling in microglial activation and enhanced inflammatory cytokine expression after stroke. 


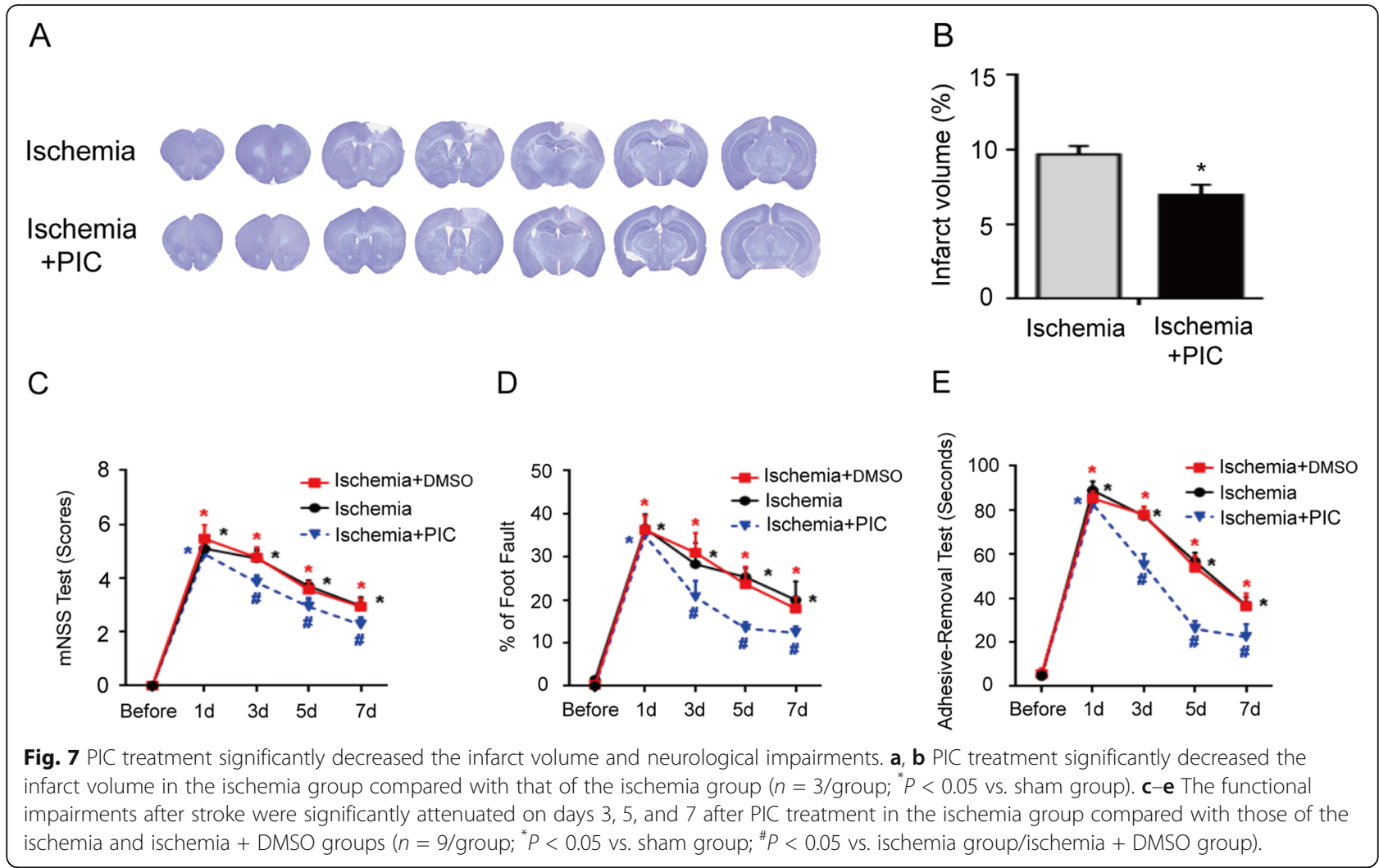

LAM and PIC decreases TNF- $a$ and iNOS production by inhibiting Dectin-1/Syk signaling in primary microglial cells with OGD/R-induced injury in vitro

The present study further investigated the proinflammatory effect of Dectin-1/Syk signaling after primary microglial cells were exposed to OGD/R-induced inflammation. As presented in Fig. 10a, b, the Dectin-1, p-Syk, TNF- $\alpha$ and iNOS expression levels were significantly increased in primary microglial cells following OGD/R induction. In addition, LAM pretreatment significantly decreased the Dectin-1 and p-Syk expression levels. At the same time, TNF- $\alpha$ and iNOS production was significantly decreased in primary microglial cells following LAM treatment $(n=3$ /group; $P<0.05)$. Figure $10 \mathrm{c}$, $\mathrm{d}$ shows that $\mathrm{p}$-Syk expression was significantly inhibited following PIC pretreatment, and PIC treatment also significantly decreased $\mathrm{p}-\mathrm{Syk}$, TNF- $\alpha$, and iNOS production in the OGD/R-induced primary microglial cells $(n=3$ / group; $P<0.05)$.

Knockdown of Dectin-1 or Syk inhibits production of proinflammatory cytokines TNF- $a$ and iNOS in BV2 microglial cells following $O G D / R$ stimulation

In order to further precisely evaluate the function of Dectin-1/Syk signaling to regulate TNF- $\alpha$ and iNOS,
BV2 cells were stimulated with OGD/R following transfection with Dectin-1 siRNA or Syk siRNA. Figure 11a, b shows that knockdown of Dectin-1 downregulated the expression of $\mathrm{p}-\mathrm{Syk}, \mathrm{TNF}-\alpha$, and iNOS in BV2 cells in the OGD/R + Dectin-1 siRNA group compared in the OGD/R + control siRNA group $(n=$ 3/group; $P<0.05$ ). Similarly, it was revealed that the production of p-Syk, TNF- $\alpha$, and iNOS in BV2 cells was significantly decreased in the $\mathrm{OGD} / \mathrm{R}+\mathrm{Syk}$ siRNA group compared in the OGD/R + control siRNA group. The present study also demonstrated that Dectin-1 expression was significantly decreased in BV2 cells in the Dectin-1 siRNA group compared in the control siRNA group, and the Syk expression was decreased in BV2 cells in Syk siRNA group compared in the control siRNA group $(n=3$ /group; $P<$ 0.05). These data suggested that knockdown of Dectin-1 or Syk ameliorate inflammation progression in BV2 microglial cells with OGD/R treatment.

\section{LAM and PIC decreases TNF- $a$ and iNOS production by inhibiting Dectin-1/Syk signaling in BV2 microglial cells with LPS-induced injury in vitro}

In order to further investigate the proinflammatory effect of Dectin-1/Syk signaling in brain tissue after a 


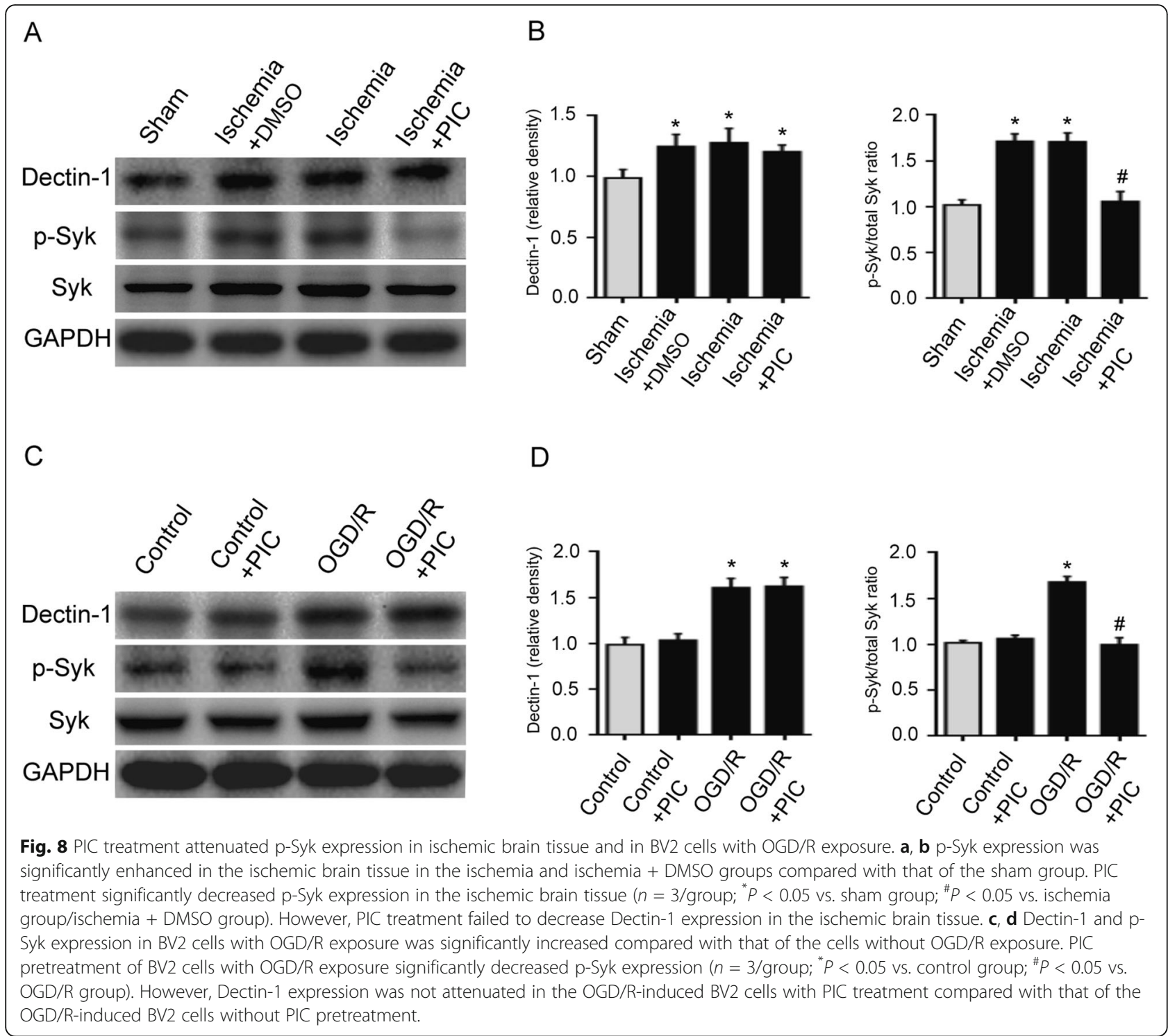

stroke, BV2 cells were exposed to LPS-induced inflammation. As presented in Fig. 12a, b, the Dectin-1 and pSyk expression levels were significantly increased in the BV2 cells at 3, 6, 12, and $24 \mathrm{~h}$ after LPS induction. The $24 \mathrm{~h}$ was selected as the LPS induction time point in BV2 cells in the subsequent experiments. Figure 12c, d shows that LAM pretreatment significantly decreased the Dectin-1 and p-Syk expression levels. At the same time, TNF- $\alpha$ and iNOS production was significantly decreased in the BV2 cells after LAM treatment. Figure $12 \mathrm{e}$, f shows that $\mathrm{p}$-Syk expression was significantly inhibited following PIC pretreatment, but no significant difference in Dectin-1 expression was observed between the LPS and LPS + PIC groups. PIC treatment also significantly decreased TNF- $\alpha$ and iNOS production in the LPS-induced BV2 cells.

\section{Discussion}

The present study demonstrated that the Dectin-1, Syk, p-Syk, TNF- $\alpha$, and iNOS expression levels were significantly increased in ischemic brain tissue after a stroke. Either Dectin-1 antagonist (LAM) or Syk inhibitor (PIC) treatment significantly decreased the expression levels of these proteins in the ischemic brain tissue. At the same time, the present study also revealed that LAM or PIC treatment significantly decreased the infarct volume and improved the functional outcomes after a stroke. Similar results were observed in the in vitro experiments. Taken together, the in vivo and complementary in vitro data support the hypothesis that Dectin-1/Syk signaling plays a vital role in neuroinflammation after a stroke. 


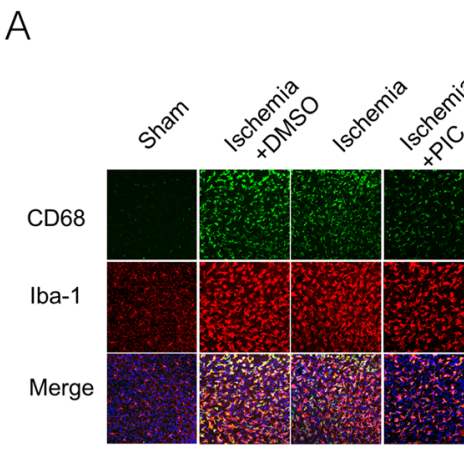

C

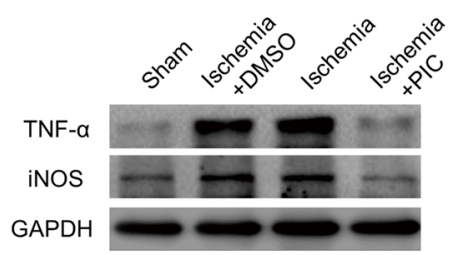

$E$

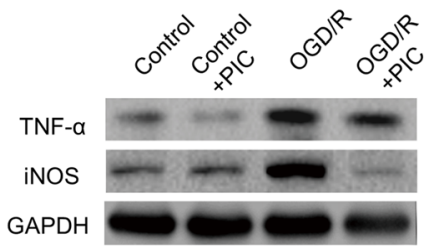

B
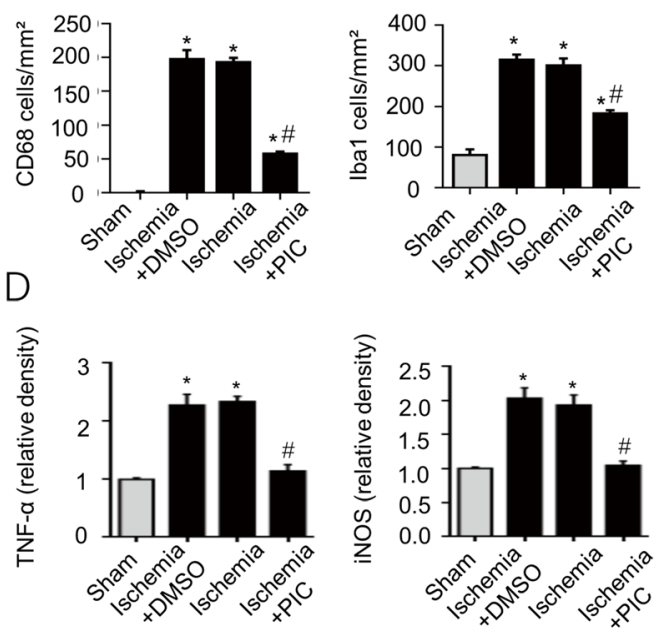

$\mathrm{F}$

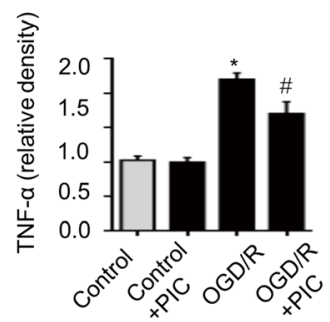

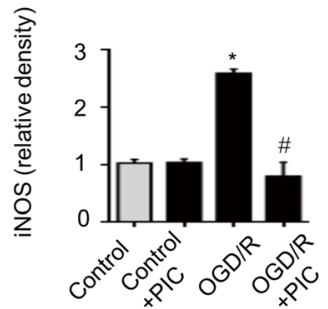

Fig. 9 PIC treatment inhibited microglial activation and decreased TNF-a and iNOS expression in the ischemic brain tissue and BV2 cells with OGD/R exposure. $\mathbf{a}$, $\mathbf{b}$ lba-1 and CD68 staining showed that microglial activation was significantly enhanced in the ischemic brain tissue 3 days after stroke compared with that of the brain tissue in the sham group. PIC treatment significantly attenuated microglial activation in the brain tissue (scale bar, $50 \mu \mathrm{m} ; n=3 /$ group $^{*} P<0.05$ vs. sham group; ${ }^{\#} P<0.05$ vs. ischemia group/ischemia + DMSO group). However, no significant difference was noted between the ischemic and DMSO groups. $\mathbf{c}$, d TNF- $a$ and iNOS expression was significantly enhanced in the ischemic brain tissue at 3 days after stroke compared with that of the brain tissue in the sham group. PIC treatment significantly decreased TNF-a and iNOS expression in the ischemic brain tissue ( $n=3 /$ group; $^{*} P<0.05$ vs. sham group; ${ }^{\#} P<0.05$ vs. ischemia group/ischemia + DMSO group). e, f BV2 cells with OGD/R exposure exhibited significantly increased TNF-a and iNOS expression compared with that of BV2 cells without OGD/R exposure. PIC pretreatment significantly inhibited TNF-a and iNOS expression in BV2 cells with OGD/R exposure compared with that of the OGD/ R group ( $n=3 /$ group; $^{*} P<0.05$ vs. control group; ${ }^{\#} P<0.05$ vs. OGD/R group). However, PIC pretreatment failed to decrease TNF-a and iNOS expression in BV2 cells without OGD/R exposure

Microglia are the resident mononuclear phagocytic cells that are critical for inflammatory responses in the central nervous system (CNS). The most common distinguishing feature of the microglia is their rapid activation in response to pathological changes in the CNS, such as ischemia [33]. Dectin-1 is expressed at a low level in the brain but is strongly upregulated following exposure to various stimuli, such as ischemia and injury [34, 35]. Dectin-1 has been reported to activate the NLRP3 (NLR family, pyrin domaincontaining 3) inflammasome and enhance IL- $1 \beta$ production [36-38]. Activation of Dectin-1 can cause macrophage-mediated demyelination and axonal injury, and blockade of Dectin-1 can decrease inflammatory macrophage-mediated injury following spinal cord injury [39]. A low-fat diet with caloric restriction decreases the expression of Dectin-1 and then attenuates white matter microglia activation during aging [40]. It has also been demonstrated that Dectin-1 signaling can trigger neuroinflammation and enable repair of injured central nervous system neurons [41]. The present study demonstrated that Dectin-1 was significantly increased in ischemic brain tissue following a stroke, and in the OGD/R-treated BV2 cells and 


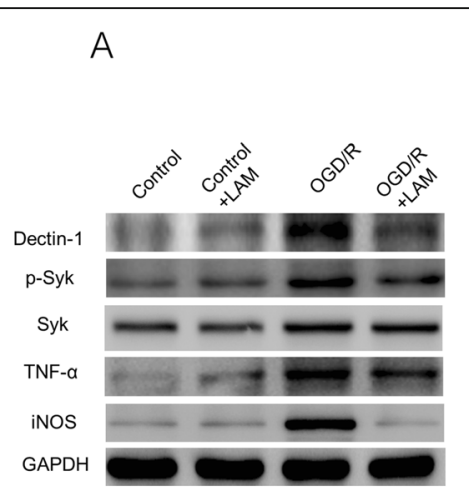

C

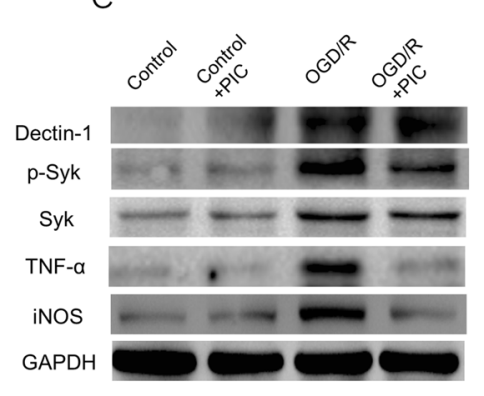

$\mathrm{B}$
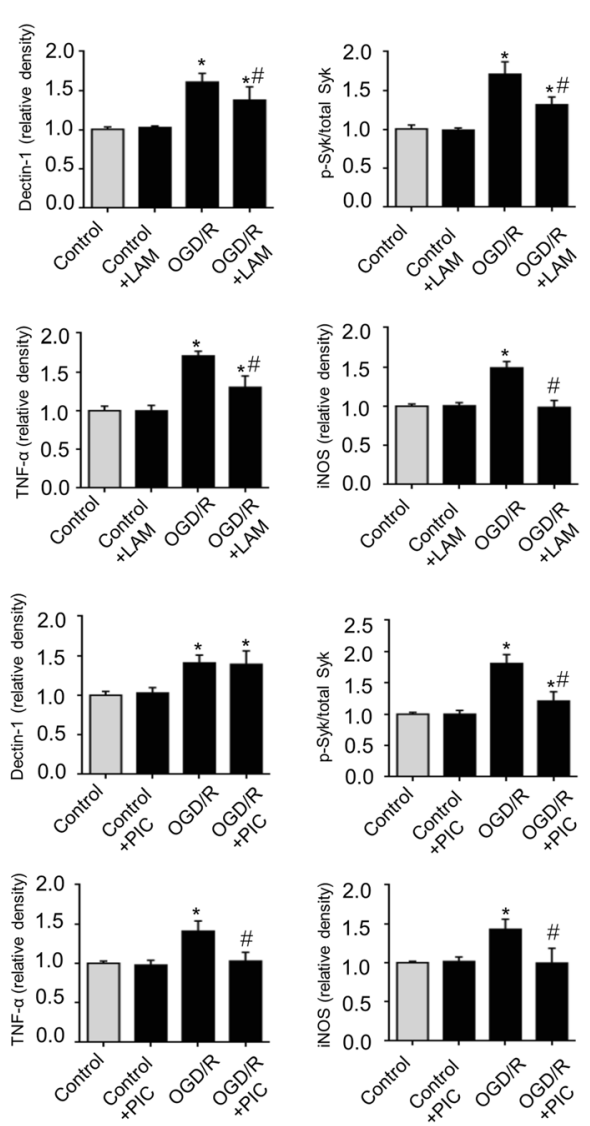

Fig. 10 Dectin-1, Syk and p-Syk expression was significantly increased in primary microglial cells with OGD/R exposure. LAM/PIC pretreatment significantly decreased p-Syk, TNF-a, and iNOS expression in primary microglial cells following OGD/R exposure. a, b Dectin-1, p-Syk, TNF-a, and iNOS expression levels were significantly enhanced in primary microglial cells with OGD/R exposure compared with primary microglial cells without OGD/R exposure. LAM pretreatment significantly decreased the expression levels of Dectin-1, p-Syk, TNF-a, and iNOS in primary microglial cells with OGD/R exposure ( $n=3$ /group; ${ }^{*} P<0.05$ vs. control group; ${ }^{~} P<0.05$ vs. OGD/R group). $\mathbf{c}$, $\mathbf{d}$ PIC pretreatment significantly inhibited p-Syk, TNF-a, and iNOS expression in primary microglial cells with OGD/R exposure compared with cells without OGD/R exposure $(n=$ 3/group; ${ }^{*} P<0.05$ vs. control group; ${ }^{*} P<0.05$ vs. OGD/R group)

primary microglia. The number of activated microglia were also enhanced after a stroke. Dectin-1 antagonist (LAM) treatment significantly decreased the expression of the aforementioned proteins and attenuated the number of activated microglia. It was also revealed that the blockade of Dectin-1 attenuated the brain infarct volume and decreased neurological deficits and microglial activation after a stroke. These data suggest that Dectin-1 overexpression may exert deleterious effects on the brain tissue and enhance neuroinflammation following ischemic stroke.

Syk, highly expressed in the microglia, plays a vital role in the inflammatory responses after ischemic stroke [42]. The ligands produced by necrotic cells bind to the receptor of Dectin-1, resulting in recruitment and activation of Syk [43-45]. Syk inhibitor PIC decreases neuronal damage after retinal ischemia-reperfusion injury $[46,47]$. Previous studies have demonstrated that
Dectin-1 can activate Syk-dependent intracellular signaling cascades [48]. Furthermore, the Dectin-1/Syk signaling pathway is involved in ROS generation and NLRP3 activation in response to $\beta$-glucan particles $[36,49,50]$. Activated Syk (p-Syk) leads to subsequent activation of downstream signaling molecules, such as $\mathrm{p} 85$, PKB, PDK1, and NF- $\mathrm{KB}$, resulting in the expression of proinflammatory genes, including TNF- $\alpha$, COX-2, and iNOS [51-54]. The present study demonstrated that Syk and p-Syk were significantly increased in the ischemic brain tissue after a stroke, as well as in the OGD/R model. Syk inhibitor (PIC) treatment significantly attenuated p-Syk, TNF- $\alpha$, and iNOS expression in the ischemic brain tissue after a stroke and in the OGD/R model. Other inflammatory mediators such as JNK, p38 MAPK, and NF$\mathrm{kB}$ have been linked to microglia activation [55-60] and would be assessed in future work. The present study also revealed that the Syk inhibitor decreased microglial 
A

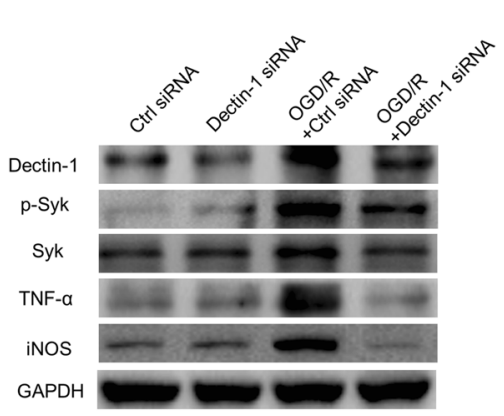

C

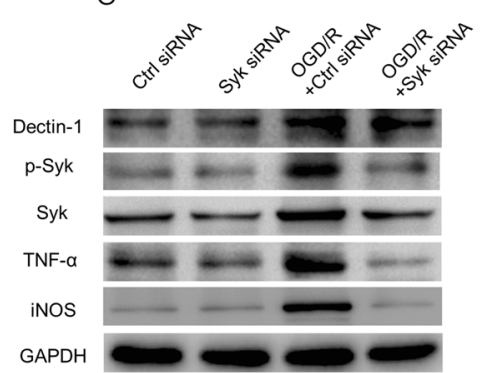

B
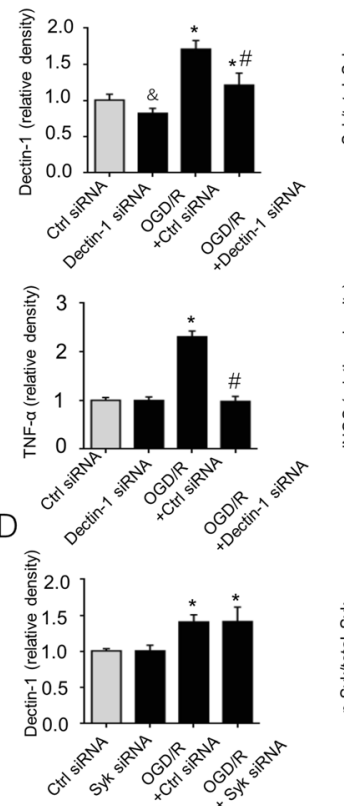

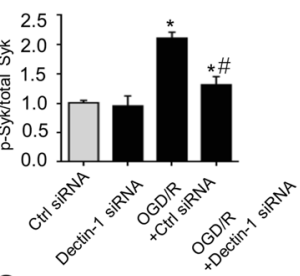

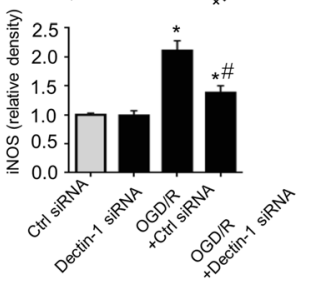

$\underbrace{2.0}_{0.0}$

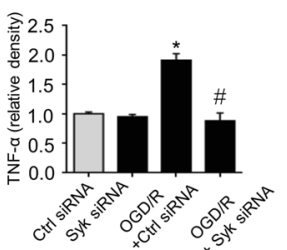

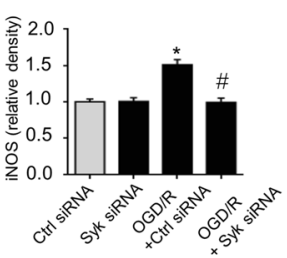

Fig. 11 Effects of knockdown Dectin-1 or Syk on inflammatory responses in OGD/R-induced BV2 cells. a, b The Dectin-1 siRNA decreased Dectin1 expression in BV2 cells with OGD/R exposure ( $n=3 /$ group; ${ }^{\&} P<0.05$ vs. control siRNA group). The expression levels of $p-S y k$, TNF-a, and iNOS were also downregulated in OGD/R + Dectin-1 siRNA group compared with that of the BV2 cells in OGD/R + control siRNA group ( $n=3 / g r o u p ;$ ${ }^{*} P<0.05$ vs. control siRNA group; ${ }^{P} P<0.05$ vs. OGD/R + control siRNA group). $\mathbf{c}$, $\mathbf{d}$ The Syk siRNA decreased Syk expression in BV2 cells ( $n=3 /$ group; ${ }^{\&} P<0.05$ vs. control siRNA group). Knockdown Syk also attenuated the production of p-Syk, TNF-a, and iNOS in BV2 cells in the OGD/R + Syk siRNA group compared with the OGD/R + control siRNA group $\left(n=3 /\right.$ group; ${ }^{*} P<0.05$ vs. control siRNA group; ${ }^{\#} P<0.05$ vs. OGD/R + control siRNA group)

activation, the brain infarct volume, and neurological deficits after a stroke. These data suggest that Syk may also exert harmful effects on brain tissue and enhance neuroinflammation after an ischemic stroke.

\section{Conclusions}

The present study demonstrated that Dectin-1, Syk, and p-Syk expression was significantly increased after a stroke both in vivo and in vitro. Treatment of ischemic stroke with a Dectin-1 antagonist or a Syk inhibitor significantly decreased microglial activation, the brain infarct volume, neurological impairment, and production of the proinflammatory cytokines TNF- $\alpha$ and iNOS after ischemic stroke. The present study may offer new ideas for effective treatment of patients who have suffered from a stroke. Further studies of the pathophysiological functions of Dectin-1/Syk signaling in the activated inflammatory response may prove beneficial for clinical applications.

\section{Supplementary information}

Supplementary information accompanies this paper at https://doi.org/10. 1186/s12974-019-1693-z.

Additional file 1. The optimal dose for LAM and PIC in BV2 cells.

\section{Abbreviations}

Dectin-1: Dendritic cell-associated C-type lectin-1; Syk: Spleen tyrosine kinase; p-Syk: Phosphorylated spleen tyrosine kinase; TNF-a: Tumor necrosis factor-a; iNOS: Inducible nitric oxide synthase; OGD/R: Oxygen-glucose deprivation/ reoxygenation; LAM: Laminarin; PIC: Piceatannol; LPS: Lipopolysaccharide; DC: Dendritic cell; ITAM: Immune-receptor tyrosine-based activation motif; CLR: C-type lectin receptor; SH2: Src homology-2 domains; CLEC2: C-type lectin-like receptor 2; CLEC9A: C-type lectin domain-containing 9A; DMSO: Dimethyl sulfoxide; mNSS: Modified neurological severity score; DMEM: Dulbecco's modified Eagle's medium; PBS: Phosphate-buffered saline; PKB: Protein kinase B; PDK1: Phosphoinositide-dependent protein kinase-1; NF-kB: Nuclear factor kappa B; COX-2: Cyclooxygenase-2; ROS: Reactive oxygen species; NLRP3: NLR family pyrin domain-containing 3; DAMPs: Damage-associated molecular patterns 
A
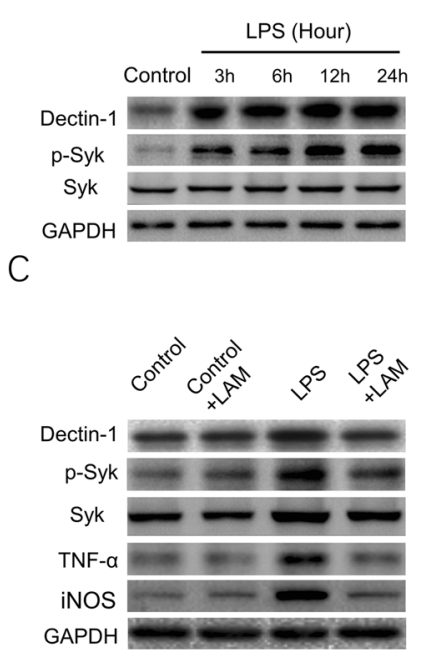

E

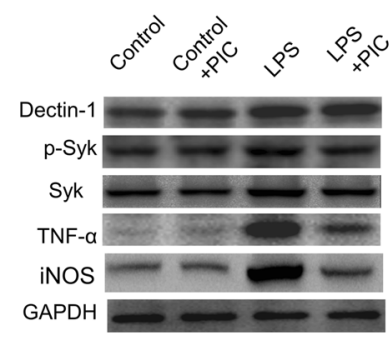

B
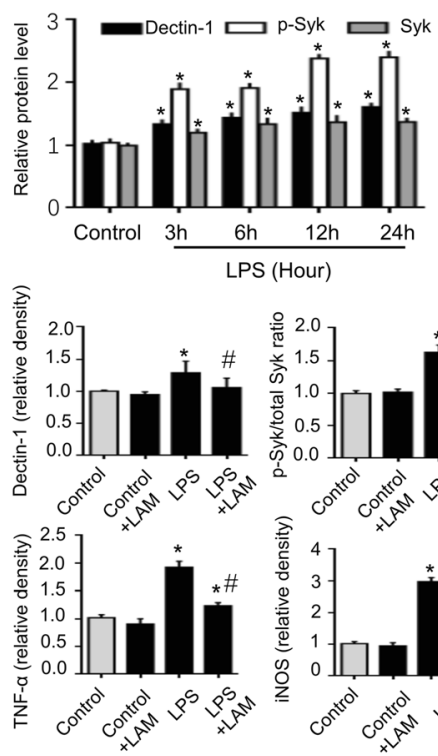

$\mathrm{F}$ 产

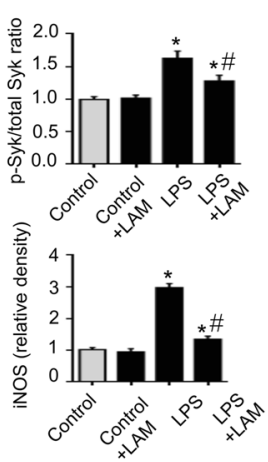

Fig. 12 Dectin-1, Syk, and p-Syk expression levels are significantly increased in LPS-induced BV2 cells. LAM/PIC pretreatment significantly decreased p-Syk, TNF-a, and iNOS expression in BV2 cells following LPS exposure. In addition, Dectin-1 expression was significantly decreased in the LPS-induced BV2 cells following LAM pretreatment. a, b The Dectin-1 and p-Syk expression levels were significantly higher at 3, 6, 12, and 24 $h$ in the BV2 cells following LPS exposure compared with in the BV2 cells without LPS exposure ( $n=3 /$ group; ${ }^{*} P<0.05$ vs. control group). Therefore, $24 \mathrm{~h}$ was selected as the optimal time point for BV2 cells exposed to LPS. $\mathbf{c}$, $\mathbf{d}$ Dectin-1, p-Syk, TNF-a, and iNOS expression was significantly enhanced in BV2 cells with $24 \mathrm{~h}$ of LPS exposure compared with that of BV2 cells without LPS exposure. LAM pretreatment significantly decreased the expression levels of the aforementioned proteins in BV2 cells with $24 \mathrm{~h}$ of LPS exposure $\left(n=3 /\right.$ group; ${ }^{*} P<0.05$ vs. control group; ${ }^{~} P<0.05$ vs. LPS group). e, f BV2 cells with LPS exposure demonstrated significantly increased Dectin-1, p-Syk, TNF-a, and iNOS expression levels compared with that of BV2 cells without LPS exposure. PIC pretreatment significantly inhibited Syk, TNF-a, and iNOS expression in BV2 cells with LPS exposure compared with that of the LPS group ( $n=3 /$ group; ${ }^{*} P<0.05$ vs. control group; ${ }^{\#} P<0.05$ vs. LPS group). However, PIC pretreatment failed to decrease Dectin-1 expression in BV2 cells with PIC pretreatment

\section{Acknowledgements}

The authors would like to thank members of Dr Cui's laboratory for their helpful discussions and suggestions.

\section{Authors' contributions}

$\mathrm{XY}, \mathrm{QH}$, and WM contributed equally to this work. All authors read and approved the final manuscript.

\section{Funding}

The present study was supported by the National Natural Science Foundation of China (grant nos. 81971134 and 81571155 to Dr. Ye and grant nos. 81571210 and 81771282 to Dr. Cui), the National Natural Science Foundation of Jiangsu Province (grant nos. BK20191152, BK20150209 and BL2014031), the Natural Science Foundation of the Higher Education Institutions of Jiangsu Province (grant no. 17KJB320017), Jiangsu Provincial
Medical Youth Talent (grant no. QNRC2016788), Jiangsu Commission of Heath (grant no. LGY2019086), Xuzhou Key Research and Development Program (grant nos. KC18055 and KC19131), Xuzhou Innovation Capacity Building Program (grant no. KC19239), Suqian Science and Technology Plan (grant no. S201714), and the Summit of Six Top Talents Program of Jiangsu Province (grant no. 2017-WSN-118).

\section{Availability of data and materials}

The datasets used and/or analyzed during the present study are available from the corresponding author upon reasonable request.

\section{Ethics approval and consent to participate}

All animal studies were conducted in compliance with protocols approved by the Jiangsu Provincial Animal Care, and all experiments conducted were 
in accordance with the standards and procedures of the ethics committee of Xuzhou Medical University.

\section{Consent for publication}

Not applicable.

\section{Competing interests}

The authors declare that they have no competing interests.

\section{Author details}

${ }^{1}$ Institute of Stroke Center and Department of Neurology, The Affiliated Hospital of Xuzhou Medical University, Xuzhou Medical University, Xuzhou, People's Republic of China. 'Department of Neurology, Second Affiliated Hospital of Xuzhou Medical University, Xuzhou, Xuzhou, People's Republic of China. ${ }^{3}$ Department of Neurology, Drum Tower Hospital, Medical School of Nanjing University, Nanjing, People's Republic of China. ${ }^{4}$ Department of Rehabilitation Medicine, Linyi Cancer Hospital, Shandong, People's Republic of China. ${ }^{5}$ Department of Neurology, Suqian People's Hospital of Nanjing Drum tower Hospital Group, Suqian, Jiangsu, People's Republic of China.

Received: 8 November 2019 Accepted: 26 December 2019

Published online: 11 January 2020

\section{References}

1. Chamorro A, Meisel A, Planas AM, Urra X, van de Beek D, Veltkamp R. The immunology of acute stroke. Nat Rev Neurol. 2012;8:401-10.

2. Gao L, Dong Q, Song Z, Shen F, Shi J, Li Y. NLRP3 inflammasome: a promising target in ischemic stroke. Inflamm Res. 2017;66:17-24.

3. ladecola C, Anrather J. The immunology of stroke: from mechanisms to translation. Nat Med. 2011:17:796-808.

4. Abulafia DP, de Rivero Vaccari JP, Lozano JD, Lotocki G, Keane RW, Dietrich WD. Inhibition of the inflammasome complex reduces the inflammatory response after thromboembolic stroke in mice. J Cereb Blood Flow Metab. 2009;29:534-44.

5. Jung JE, Kim GS, Chan PH. Neuroprotection by interleukin-6 is mediated by signal transducer and activator of transcription 3 and antioxidative signaling in ischemic stroke. Stroke. 2011;42:3574-9.

6. Poltorak A, He X, Smirnova I, Liu MY, Van Huffel C, Du X, Birdwell D, Alejos E, Silva M, Galanos C, et al. Defective LPS signaling in C3H/HeJ and C57BL/ 10ScCr mice: mutations in Tlr4 gene. Science. 1998;282:2085-8.

7. Tang SC, Arumugam TV, Xu X, Cheng A, Mughal MR, Jo DG, Lathia JD, Sile DA, Chigurupati S, Ouyang $X$, et al. Pivotal role for neuronal Toll-like receptors in ischemic brain injury and functional deficits. Proc Natl Acad Sci U S A. 2007;104:13798-803.

8. Shichita T, Hasegawa E, Kimura A, Morita R, Sakaguchi R, Takada I, Sekiya T, Ooboshi H, Kitazono T, Yanagawa T, et al. Peroxiredoxin family proteins are key initiators of post-ischemic inflammation in the brain. Nat Med. 2012;18:911-7.

9. Willment JA, Marshall AS, Reid DM, Williams DL, Wong SY, Gordon S, Brown GD. The human beta-glucan receptor is widely expressed and functionally equivalent to murine Dectin-1 on primary cells. Eur J Immunol. 2005;35: 1539-47.

10. Martin B, Hirota K, Cua DJ, Stockinger B, Veldhoen M. Interleukin-17producing gammadelta $T$ cells selectively expand in response to pathogen products and environmental signals. Immunity. 2009:31:321-30.

11. Sun WK, Lu X, Li X, Sun QY, Su X, Song Y, Sun HM, Shi Y. Dectin-1 is inducible and plays a crucial role in Aspergillus-induced innate immune responses in human bronchial epithelial cells. Eur J Clin Microbiol Infect Dis. 2012:31:2755-64.

12. Bertuzzi M, Schrettl M, Alcazar-Fuoli L, Cairns TC, Munoz A, Walker LA, Herbst S, Safari M, Cheverton AM, Chen D, et al. The pH-responsive PacC transcription factor of Aspergillus fumigatus governs epithelial entry and tissue invasion during pulmonary aspergillosis. PLoS Pathog. 2014;10: e1004413.

13. Park JS, Gamboni-Robertson F, He Q, Svetkauskaite D, Kim JY, Strassheim D, Sohn JW, Yamada S, Maruyama I, Banerjee A, et al. High mobility group box 1 protein interacts with multiple Toll-like receptors. Am J Physiol Cell Physiol. 2006;290:C917-24.

14. Frontera JA, Aledort L, Gordon E, Egorova N, Moyle H, Patel A, Bederson JB, Sehba F. Early platelet activation, inflammation and acute brain injury after a subarachnoid hemorrhage: a pilot study. J Thromb Haemost. 2012;10:711-3.
15. Lamkanfi M, Dixit VM. Inflammasomes and their roles in health and disease. Annu Rev Cell Dev Biol. 2012;28:137-61.

16. Shichita T, Ago T, Kamouchi M, Kitazono T, Yoshimura A, Ooboshi H. Novel therapeutic strategies targeting innate immune responses and early inflammation after stroke. J Neurochem. 2012;123(Suppl 2):29-38.

17. Riccaboni M, Bianchi I, Petrillo P. Spleen tyrosine kinases: biology, therapeutic targets and drugs. Drug Discov Today. 2010;15:517-30.

18. Duta F, Ulanova M, Seidel D, Puttagunta L, Musat-Marcu S, Harrod KS, Schreiber AD, Steinhoff $U$, Befus AD. Differential expression of spleen tyrosine kinase Syk isoforms in tissues: Effects of the microbial flora. Histochem Cell Biol. 2006;126:495-505.

19. Pamuk ON, Tsokos GC. Spleen tyrosine kinase inhibition in the treatment of autoimmune, allergic and autoinflammatory diseases. Arthritis Res Ther. 2010;12:222.

20. Geahlen RL, Burg DL. The role of Syk in cell signaling. Adv Exp Med Biol. 1994;365:103-9.

21. Mocsai A, Ruland J, Tybulewicz VL. The SYK tyrosine kinase: a crucial player in diverse biological functions. Nat Rev Immunol. 2010;10:387-402.

22. Turner M, Schweighoffer $E_{1}$ Colucci F, Di Santo JP, Tybulewicz VL. Tyrosine kinase SYK: essential functions for immunoreceptor signalling. Immunol Today. 2000;21:148-54.

23. Friedrich V, Flores R, Muller A, Bi W, Peerschke El, Sehba FA. Reduction of neutrophil activity decreases early microvascular injury after subarachnoid haemorrhage. J Neuroinflammation. 2011;8:103.

24. Kim JY, Kawabori M, Yenari MA. Innate inflammatory responses in stroke: mechanisms and potential therapeutic targets. Curr Med Chem. 2014;21:2076-97.

25. Ystgaard MB, Sejersted Y, Loberg EM, Lien E, Yndestad A, Saugstad OD. Early upregulation of NLRP3 in the brain of neonatal mice exposed to hypoxiaischemia: no early neuroprotective effects of NLRP3 Deficiency. Neonatology. 2015;108:211-9.

26. Kawai T, Akira $\mathrm{S}$. The role of pattern-recognition receptors in innate immunity: update on Toll-like receptors. Nat Immunol. 2010;11:373-84.

27. Ye XC, Hu JX, Li L, Li Q, Tang FL, Lin S, Sun D, Sun XD, Cui GY, Mei L, Xiong WC. Astrocytic Lrp4 (low-density lipoprotein receptor-related protein 4) contributes to ischemia-induced brain injury by regulating ATP release and adenosine-A2AR (Adenosine A2A Receptor) Signaling. Stroke. 2018:49:165-74.

28. Ye X, Shen T, Hu J, Zhang L, Zhang Y, Bao L, Cui C, Jin G, Zan K, Zhang $Z$, et al. Purinergic $2 X 7$ receptor/NLRP3 pathway triggers neuronal apoptosis after ischemic stroke in the mouse. Exp Neurol. 2017;292:46-55.

29. Chen J, Li Y, Wang L, Zhang Z, Lu D, Lu M, Chopp M. Therapeutic benefit of intravenous administration of bone marrow stromal cells after cerebral ischemia in rats. Stroke. 2001:32:1005-11.

30. Zhao Y, Wu X, Li X, Jiang LL, Gui X, Liu Y, Sun Y, Zhu B, Pina-Crespo JC, Zhang $M$, et al. TREM2 Is a receptor for beta-amyloid that mediates microglial function. Neuron. 2018;97:1023-1031.e1027.

31. Derecki NC, Cronk JC, Lu Z, Xu E, Abbott SB, Guyenet PG, Kipnis J. Wild-type microglia arrest pathology in a mouse model of Rett syndrome. Nature. 2012:484:105-9.

32. Lugo-Villarino G, Troegeler A, Balboa L, Lastrucci C, Duval C, Mercier I, Benard A, Capilla F, Al Saati T, Poincloux R, et al. The C-type lectin receptor DC-SIGN has an anti-inflammatory role in human $M(I L-4)$ macrophages in response to mycobacterium tuberculosis. Front Immunol. 2018;9:1123.

33. Eldahshan W, Fagan SC, Ergul A. Inflammation within the neurovascular unit: focus on microglia for stroke injury and recovery. Pharmacol Res. 2019; 147:104349.

34. Reid DM, Montoya M, Taylor PR, Borrow P, Gordon S, Brown GD, Wong SY. Expression of the beta-glucan receptor, Dectin-1, on murine leukocytes in situ correlates with its function in pathogen recognition and reveals potential roles in leukocyte interactions. J Leukoc Biol. 2004; 76:86-94

35. Lech M, Susanti HE, Rommele C, Grobmayr R, Gunthner R, Anders HJ. Quantitative expression of C-type lectin receptors in humans and mice. Int J Mol Sci. 2012;13:10113-31.

36. Gross O, Poeck H, Bscheider M, Dostert C, Hannesschlager N, Endres S, Hartmann G, Tardivel A, Schweighoffer E, Tybulewicz V, et al. Syk kinase signalling couples to the Nlrp3 inflammasome for anti-fungal host defence. Nature. 2009;459:433-6. 
37. Hise AG, Tomalka J, Ganesan S, Patel K, Hall BA, Brown GD, Fitzgerald KA. An essential role for the NLRP3 inflammasome in host defense against the human fungal pathogen Candida albicans. Cell Host Microbe. 2009:5:487-97.

38. Gringhuis SI, Kaptein TM, Wevers BA, Theelen B, van der Vlist M, Boekhout T, Geijtenbeek TB. Dectin-1 is an extracellular pathogen sensor for the induction and processing of IL-1beta via a noncanonical caspase- 8 inflammasome. Nat Immunol. 2012;13:246-54

39. Gensel JC, Wang Y, Guan Z, Beckwith KA, Braun KJ, Wei P, McTigue DM, Popovich PG. Toll-Like receptors and Dectin-1, a C-type lectin receptor, trigger divergent functions in CNS macrophages. J Neurosci. 2015;35:9966-76.

40. Yin Z, Raj DD, Schaafsma W, van der Heijden RA, Kooistra SM, Reijne AC, Zhang X, Moser J, Brouwer N, Heeringa P, et al. Low-fat diet with caloric restriction reduces white matter microglia activation during aging. Front Mol Neurosci. 2018;11:65.

41. Baldwin KT, Carbajal KS, Segal BM, Giger RJ. Neuroinflammation triggered by beta-glucan/dectin-1 signaling enables CNS axon regeneration. Proc Natl Acad Sci U S A. 2015:112:2581-6.

42. Pamuk ON, Lapchak PH, Rani P, Pine P, Dalle Lucca JJ, Tsokos GC. Spleen tyrosine kinase inhibition prevents tissue damage after ischemia-reperfusion. Am J Physiol Gastrointest Liver Physiol. 2010;299:G391-9.

43. Huysamen C, Willment JA, Dennehy KM, Brown GD. CLEC9A is a novel activation C-type lectin-like receptor expressed on BDCA3+ dendritic cells and a subset of monocytes. J Biol Chem. 2008;283:16693-701.

44. Yamasaki S, Ishikawa E, Sakuma M, Hara H, Ogata K, Saito T. Mincle is an ITAM-coupled activating receptor that senses damaged cells. Nat Immunol. 2008;9:1179-88

45. Sancho D, Joffre OP, Keller AM, Rogers NC, Martinez D, Hernanz-Falcon P, Rosewell I. Reis e Sousa C: Identification of a dendritic cell receptor that couples sensing of necrosis to immunity. Nature. 2009;458:899-903.

46. Chaudhary A, Fresquez TM, Naranjo MJ. Tyrosine kinase Syk associates with toll-like receptor 4 and regulates signaling in human monocytic cells. Immunol Cell Biol. 2007:85:249-56.

47. Ishizuka F, Shimazawa M, Inoue Y, Nakano Y, Ogishima H, Nakamura S, Tsuruma K, Tanaka H, Inagaki N, Hara H. Toll-like receptor 4 mediates retinal ischemia/reperfusion injury through nuclear factor-kappaB and spleen tyrosine kinase activation. Invest Ophthalmol Vis Sci. 2013;54:5807-16.

48. Rogers NC, Slack EC, Edwards AD, Nolte MA, Schulz O, Schweighoffer E, Williams DL, Gordon S, Tybulewicz VL, Brown GD. Reis e Sousa C: Sykdependent cytokine induction by Dectin-1 reveals a novel pattern recognition pathway for C type lectins. Immunity. 2005;22:507-17.

49. Said-Sadier N, Padilla E, Langsley G, Ojcius DM. Aspergillus fumigatus stimulates the NLRP3 inflammasome through a pathway requiring ROS production and the Syk tyrosine kinase. PLoS One. 2010;5:e10008.

50. Kankkunen P, Teirila L, Rintahaka J, Alenius H, Wolff H. Matikainen S: (1,3)beta-glucans activate both dectin-1 and NLRP3 inflammasome in human macrophages. J Immunol. 2010;184:6335-42.

51. Seok Yang W, Lee J, Woong Kim T, Hye Kim J, Lee S, Hee Rhee M, Hong S, Youl Cho J. Src/NF-kappaB-targeted inhibition of LPS-induced macrophage activation and dextran sodium sulphate-induced colitis by Archidendron clypearia methanol extract. J Ethnopharmacol. 2012;142:287-93.

52. Yu T, Lee S, Yang WS, Jang HJ, Lee YJ, Kim TW, Kim SY, Lee J, Cho JY. The ability of an ethanol extract of Cinnamomum cassia to inhibit Src and spleen tyrosine kinase activity contributes to its anti-inflammatory action. J Ethnopharmacol. 2012;139:566-73.

53. Jeong D, Yang WS, Yang Y, Nam G, Kim JH, Yoon DH, Noh HJ, Lee S, Kim TW, Sung GH, Cho JY. In vitro and in vivo anti-inflammatory effect of Rhodomyrtus tomentosa methanol extract. J Ethnopharmacol. 2013; 146:205-13.

54. Yoon JY, Jeong HY, Kim SH, Kim HG, Nam G, Kim JP, Yoon DH, Hwang H, Kimc TW, Hong S, Cho JY. Methanol extract of Evodia lepta displays Syk/Srctargeted anti-inflammatory activity. J Ethnopharmacol. 2013;148:999-1007.

55. Guo G, Bhat NR. Hypoxia/reoxygenation differentially modulates NF-kappaB activation and iNOS expression in astrocytes and microglia. Antioxid Redox Signal. 2006:8:911-8.

56. Yang CS, Yuk JM, Shin DM, Kang J, Lee SJ, Jo EK. Secretory phospholipase A2 plays an essential role in microglial inflammatory responses to Mycobacterium tuberculosis. Glia. 2009;57:1091-103.

57. Huang C, Wang Y, Wang J, Yao W, Chen X, Zhang W. TSG $(2,3,4$ ', 5tetrahydroxystilbene 2-O-beta-D-glucoside) suppresses induction of pro-inflammatory factors by attenuating the binding activity of nuclear factor-kappaB in microglia. J Neuroinflammation. 2013;10:129.

58. Bhatia HS, Baron J, Hagl S, Eckert GP, Fiebich BL. Rice bran derivatives alleviate microglia activation: possible involvement of MAPK pathway. J Neuroinflammation. 2016;13:148

59. Benakis C, Bonny C, Hirt L. JNK inhibition and inflammation after cerebral ischemia. Brain Behav Immun. 2010;24:800-11.

60. Dhungana H, Huuskonen MT, Jaronen M, Lemarchant S, Ali H, KeksaGoldsteine V, Goldsteins G, Kanninen KM, Koistinaho J, Malm T. Sulfosuccinimidyl oleate sodium is neuroprotective and alleviates strokeinduced neuroinflammation. J Neuroinflammation. 2017:14:237.

\section{Publisher's Note}

Springer Nature remains neutral with regard to jurisdictional claims in published maps and institutional affiliations.
Ready to submit your research? Choose BMC and benefit from:

- fast, convenient online submission

- thorough peer review by experienced researchers in your field

- rapid publication on acceptance

- support for research data, including large and complex data types

- gold Open Access which fosters wider collaboration and increased citations

- maximum visibility for your research: over $100 \mathrm{M}$ website views per year

At BMC, research is always in progress.

Learn more biomedcentral.com/submissions 